\title{
Metastatic renal cell carcinoma presenting as a duodenal mass
}

\author{
Spyridon Vrakas ${ }^{1}$, Epameinondas Skouloudis ${ }^{1}$, Georgios Koutoufaris ${ }^{1}$, Kassiani \\ Manoloudaki $^{1}$, and Vasilis Xourgias ${ }^{1}$ \\ ${ }^{1}$ Peripheral General Hospital of Peiraias Tzaneio
}

December 8, 2021

\begin{abstract}
We report a case of renal cell carcinoma metastasis to the duodenum.

Metastatic renal cell carcinoma presenting as a duodenal mass

Spyridon Vrakas ${ }^{1}$, Epameinondas Skouloudis ${ }^{1}$, Georgios Koutoufaris ${ }^{1}$, Kassiani Manoloudaki ${ }^{2}$, Vasilis Xourgias ${ }^{1}$

${ }^{1}$ Department of Gastroenterology, Tzaneion General Hospital, Piraeus, Greece 2Department of Pathology, Tzaneion General Hospital, Piraeus, Greece
\end{abstract}

Correspondence

Spyridon Vrakas, Tzaneion General Hospital, Zanni \& Afentouli 1 18536, Piraeus, Greece, Email: sbrakas@yahoo.gr

\section{Key Clinical Message}

Renal cell carcinoma metastasis rarely affects the gastrointestinal tract and should be included in the differential diagnosis in patients with iron deficiency anemia and a history of RCC.

\section{Abstract}

We report a case of renal cell carcinoma metastasis to the duodenum.

\section{Keywords}

Renal cell carcinoma, Metastasis, Duodenum

A 55-year old woman was admitted to our hospital for iron deficiency anemia, with hemoglobin $7.4 \mathrm{~g} / \mathrm{dl}$ and low transferrin saturation (9\%). From medical history, she underwent right radical nephrectomy due to clear cell carcinoma eight years ago. The patient was transfused with 2 units of red blood cells and underwent colonoscopy without pathological findings. Esophagogastroduodenoscopy revealed a mass in the second part of the duodenum (Figure 1) and biopsies were taken. Histopathology examination showed sheets of clear cells (Figure 2). Immunohistochemistry was positive for CD10, PAX8, EMA, Cam5-2, vimentin, while CK7 was negative (Figure 2). Diagnosis of metastatic renal cell carcinoma (RCC) was confirmed. Computer tomography showed metastases to the lungs, liver, brain and duodenum. The left kindey revealed no abnormalities. Oncology department was consulted and patient was planned for immunotherapy.

Recurrence of RCC is unpredictable, and rarely affects the gastrointestinal tract. RCC recurrs in the form of single or multiple metastatic lesions. The most common sites of metastases are liver, lungs, bones, and 
brain. Duodenum is a rare site of RCC metastasis ${ }^{1,2}$. The time from resection of the primary tumor until the diagnosis of metachronous metastasis varies and long term follow up is needed.

\section{CONSENT STATEMENT}

Informed consent has been obtained from patient for the publication of this clinical image.

\section{AUTHOR CONTRIBUTIONS}

VS, ES, MK and XV: contributed to the writing and approval of the final manuscript.

\section{CONFLICT OF INTEREST}

None declared.

\section{ETHICAL STATEMENT}

Written informed consent was obtained from patient. This case report did not receive any funding. Authors have access to all source data for this case report.

\section{DATA AVAILABILITY STATEMENT}

Data supporting the findings of this study are available from the corresponding author on request.

\section{REFERENCES}

1) Saito M, Senjo H, Kanaya M, Izumiyama K, Mori A, Tanaka M, Morioka M, Miyashita K, Ishida Y. Late duodenal metastasis from renal cell carcinoma with newly developed malignant lymphoma: A case report. Clin Oncol 2018;8(4):549-552

2) Grossen A, Kastens DJ, Salem G. Metastatic Renal Cell Carcinoma to the Gastrointestinal Tract. Clin Gastroenterol Hepatol. 2020;18(13):e153.

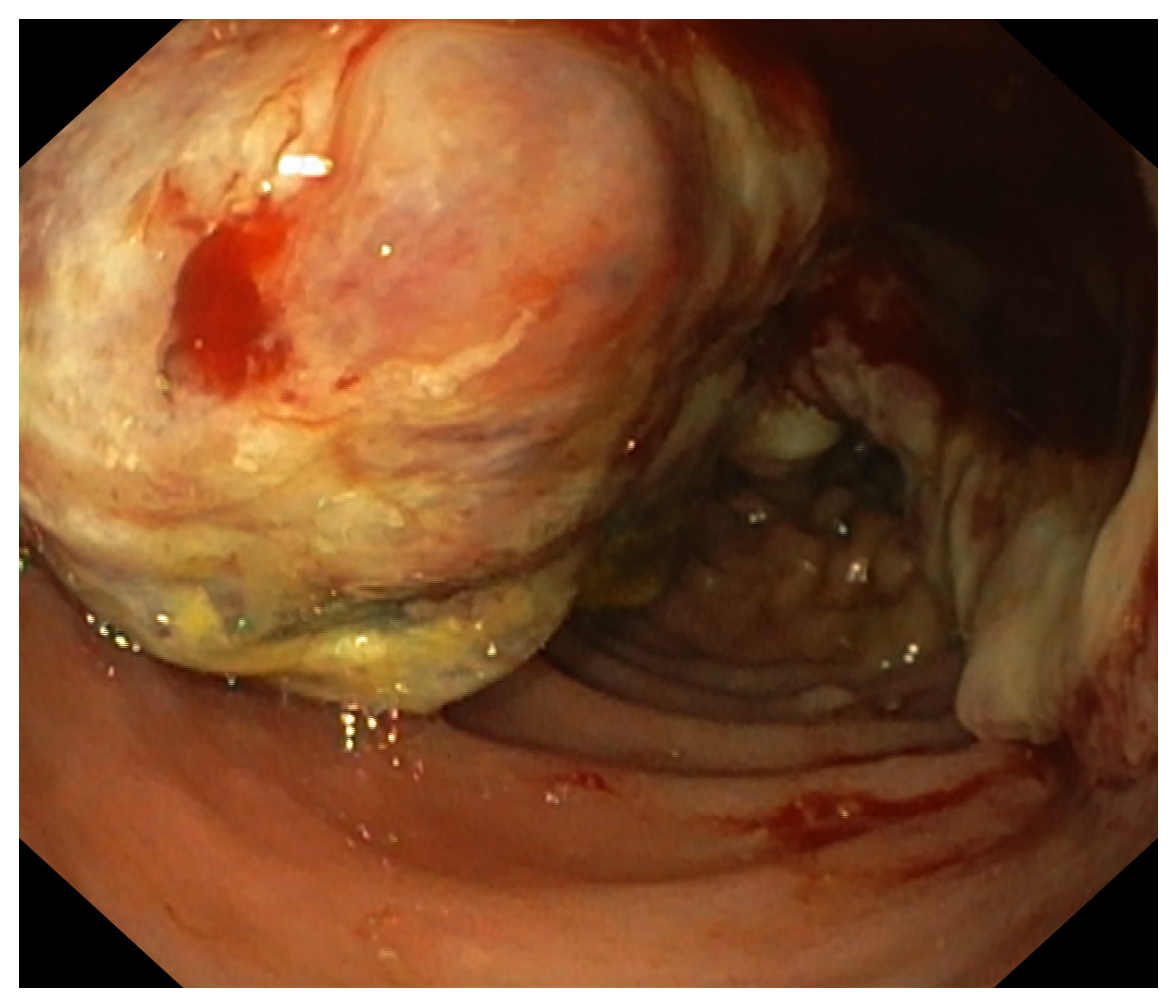



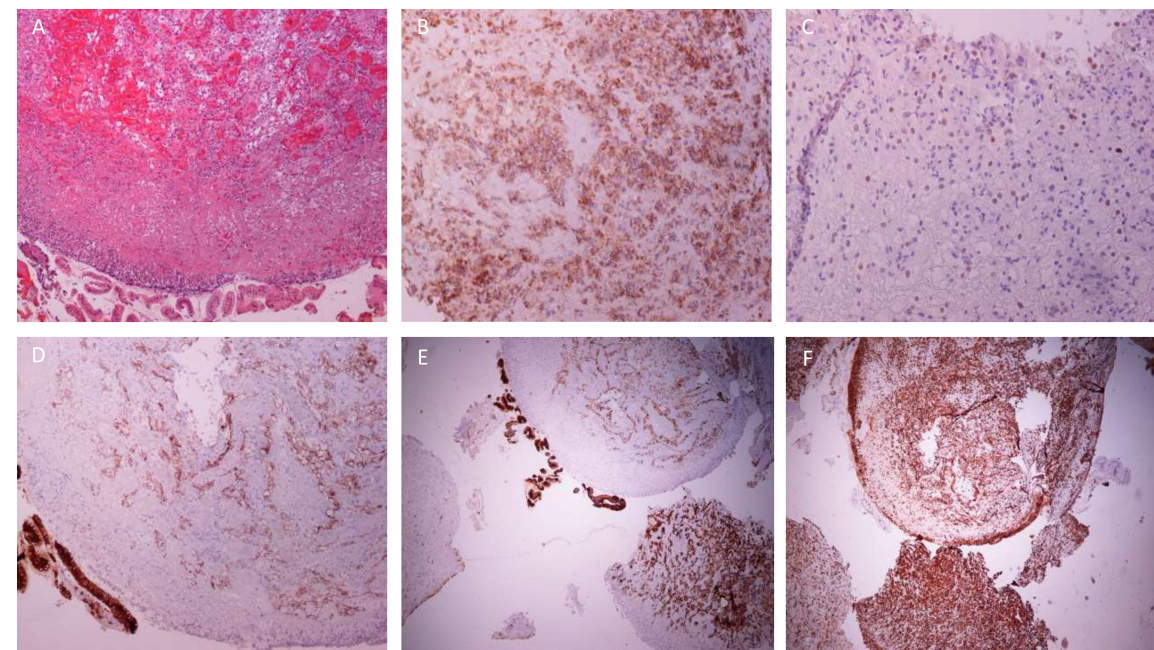